\title{
Monism and Material Constitution
}

\author{
STEPHEN BARKER \\ MARK Jago Forthcoming in Pacific Philosophical Quarterly. Draft of January 2013.
}

Abstract: Are the sculpture and the mass of gold which permanently makes it up one object or two? In this paper, we argue that the monist, who answers 'one object', cannot accommodate the asymmetry of material constitution. To say 'the mass of gold materially constitutes the sculpture, whereas the sculpture does not materially constitute the mass of gold', the monist must treat 'materially constitutes' as an Abelardian predicate, whose denotation is sensitive to the linguistic context in which it appears. We motivate this approach in terms of modal analyses of material constitution, but argue that ultimately it fails. The monist must instead accept a deflationary, symmetrical use of 'materially constitutes'. We argue that this is a serious cost for her approach.

\section{Introduction}

In this paper, we provide reasons for thinking that material constitution is an asymmetric relation and show that, as a result, those who take permanently coincident objects to be identical - monists - face a serious objection. We begin by setting the stage for the argument.

A sculptor creates a sculpture consisting of a long, thin sheet of gold, twisted into many loops and joined into a Möbius surface. (Think of Parry's Continuum sculpture.) For practical reasons, she constructs the sculpture in two halves. When she fixes them together, she creates a unified mass of gold in the form of a single gold sheet, which itself constitutes the sculpture. Later, disaster strikes and the sculpture is obliterated, so that neither sculpture, gold sheet nor unified mass of gold remains. The sculpture, the gold sheet and the mass of gold are spatially coincident throughout their existence. We take a monist to be someone who says that the sculpture, gold sheet and mass of gold are just one object (i.e., are numerically identical). A pluralist, by contrast, takes the sculpture, gold sheet and mass of gold to be numerically distinct. ${ }^{\mathrm{I}}$

Our interest in this paper is in the asymmetric notion of material constitution. ${ }^{2}$ On the face of it, this is the one-to-one relation that holds between $x$ and $y$ when $x$, in virtue of its form, arrangement, social standing or whatever, makes up $y$. In our example, the mass of gold materially constitutes the gold sheet in virtue of its cohesion and its flat, sheetlike form. The gold sheet materially constitutes the sculpture in virtue of the sculptor's input and the complex social relations in

I. The terminology comes from Fine (2003). Monists include Allan Gibbard (I975), David Lewis (I97I) and Stephen Yablo (I987). Pluralists include Fred Doepke (I982), E. J. Lowe (I983), Judith Jarvis Thomson (I997) and David Wiggins (I980).

2. Our focus here is on material constitution. Much of what we say may not be applicable to the constitution of non-material beings such as numbers or gods. 
virtue of which the artefacts she forms are held to be sculptures. ${ }^{3}$

We think material constitution is asymmetric: if $x$ materially constitutes $y$, then $y$ does not materially constitute $x$. It seems clear to us that if a cardigan is made from one very long wool thread, then the single wool thread is not made from the cardigan. That just seems intuitively right to us, and we take this to be a paradigm case of (asymmetric) material constitution. Here's a more developed reason. Claims of material constitution carry information about recipes for making things. If we tell you that the cardigan is made of one piece of thread, then we convey the information that one way of getting a cardigan is to take some thread and process it in a certain way. A single wool thread is part of at least one recipe for a cardigan.

This kind of making-recipe says: take some substance and add some structure to it. In the cases that interest us, the original substance survives the change in its structure: the thread remains, now structured to make up a cardigan. Crucially, such constructive making-recipes are asymmetric. They involve the addition of structure: the cardigan is the wool with suitable structure added. One cannot add structure to a cardigan to obtain a single thread. (One can remove structure to obtain the tread, but this is not part of the kind of constructive making-recipe that concerns us here.)

Recipes in general point to important explanatory relations in the world. We are interested in them (in part) because of in our interest in manipulating the world to get things we want. Just as causal recipes point to causal relations (Gasking I955), we think that constructive making-recipes point to material constitution. If so, then we have a reason for taking material constitution to be asymmetric. Asymmetry seems crucial to constructive making-recipes, but it is hard to see how this could be if they pointed to a symmetric (or non-symmetric) relation. If we are right about this connection, then it is plausible that our philosophical interest in material constitution is justified by our practical interest in making-recipes (and ultimately, by our interest in manipulating the world).

One may object on the grounds that the apparent asymmetry of material constitution (and perhaps of making-recipes too) is a purely pragmatic matter. Wasserman $(2004,706)$ argues that judgements about our example are asymmetric only because we are in general more interested in sculptures than in lumps of metal. On his deflationary approach, 'materially constitutes' statements are really statements about spatial coincidence (Wasserman 2004, 708), albeit with pragmatic implications not shared by the corresponding spatial coincidence statements.

We don't think that this deflationary account is plausible. Consider Cortés, melting down Aztec statues to extract gold. He had no (or very little) interest in the statues qua statues. However, if Wasserman was right, it would have

3. Material constitution should be distinguished from composition. The former is one-one whilst the latter is many-one: many gold atoms compose the mass of gold, for example. Our discussion will be restricted exclusively to material constitution, rather than composition. Phrases such as 'makes up' and 'consists of' may pick out composition as well as material constitution, depending on context. Insofar as we have a genuine, common, one-to-one and asymmetric use of 'makes up' (and 'consists of'), we have a genuine, common, one-to-one and asymmetric use of the concept of material constitution. 
been appropriate for Cortés to say: this lump of gold is made up of (materially constituted by) this statue. This isn't plausible. The disagreement between the Conquistadors and the Aztecs over what was valuable - the statues or the gold was not a dispute about whether the statues materially constituted the lumps of gold. The agreed facts of material constitution cut across their differing interests.

In short, there is a serious case for thinking that material constitution is an asymmetric relation. The rest of the paper looks at the consequences of this for the monist. We begin, in $\$ 2$, by discussing how a monist may try to save the appearance of asymmetry by adopting the Abelardian strategy (Noonan I99I), on which the target predicate is inconstant in denotation. Adopting this strategy, we then discuss analyses of material constitution which are prima facie compatible with monism $\left(\mathbb{S}_{3}\right)$. But we show that these analyses are not, in fact, compatible with monism $\left(\mathbb{S}_{4}\right)$. We discuss the implications of this argument for the monist $\left(\$_{5}\right)$ and consider a reply to our argument, on behalf of the monist $(\$ 6)$. We take our argument to show that the monist cannot accept an asymmetric reading of 'materially constitutes'. This is the main aim of the paper. $\$ 7$ is a brief conclusion.

\section{The Abelardian Approach}

In this section, we describe the Abelardian strategy (Noonan I99I), as applied to 'materially constitutes'. The guiding idea is that an Abelardian predicate may pick out a different property or relation in different linguistic contexts. In our case, a use of 'materially constitutes' is sensitive to the terms which flank it (and their order). The relation picked out in ' $a$ materially constitutes $b$ ' need not be the relation picked out in ' $b$ materially constitutes $a$ '. If those relations differ, then there is no contradiction in holding that $a=b, a$ materially constitutes $b$, and yet $b$ does not materially constitute $a$.

How can a predicate be Abelardian? Quine's example, 'is so-called', depends for its denotation on the preceding name. 'Bob is so-called' says that Bob is called 'Bob', whereas 'Jim is so-called' says that Jim is called 'Jim'. 'Is so-called' is sensitive to the spelling of the term to which it is affixed. 'Materially constitutes' is clearly not like 'is so-called' in this respect. A further (more controversial) example is given by modal predicates. According to many philosophers, a human body is essentially a physical thing but not essentially a person, whereas a person is essentially a person but not essentially a physical thing. Yet many also hold that each person is identical to her body. If person and body differ in their modal properties, then (by Leibnitz's law) person and body are in fact distinct. One can reconcile these positions by taking such modal predicates to be Abelardian. The claim is that a modal predicate may attach truly to ' $a$ ' but not to ' $b$ ' without any difference in the modal properties of $a$ and $b$.

How can a modal predicate be Abelardian? Lewis's counterpart theory is one way to explain how this can be so. On Lewis's analysis, ' $x$ is essentially $F$ ' says that all of $x$ 's counterparts are $F$ s. Counterpart relations are similarity relations, and there are many respects in which two entities may be similar or dissimilar. Context determines which aspect of similarity is relevant. Consequently, there are many 
counterpart relations, with context determining which is appropriate to evaluating a given modal claim. ${ }^{4}$ 'Context' here includes linguistic context: referring to an entity as a person may invoke a different counterpart relation than referring to the same entity as a physical body. So when Bob says that he is essentially a person, he attributes to himself the property of having only people as person-counterparts, whereas when he says that his body is not essentially a person, he is saying that he lacks the property of having only people as body-counterparts. There's no contradiction there, even if Bob is identical to his body.

In a similar way, one could take 'materially constitutes' to be Abelardian by taking it to denote a modal relation. One could give an analysis in terms of the differing persistence conditions associated with the sortals sculpture, gold sheet and mass of gold, for example. We will look at modal accounts of material constitution in more detail in $\mathbb{3}$.

An Abelardian account of material constitution must (i) explain how 'materially constitutes' is Abelardian whilst (ii) being an adequate account of material constitution. Modal accounts of material constitution $\left(\mathbb{S}_{3}\right)$ can satisfy (i) and may well be the best way to satisfy (ii), independently of the monist/pluralist debate. Non-modal Abelardian analyses of 'materially constitutes' are not promising. On Burke's dominant sortal account (Burke I994; I 997), by example, the $F$ materially constitutes the $G$ iff the $F$ is identical with the $G$ and property $G$ is the dominant sortal of that thing. Burke holds that 'an object's dominant sortal is the sortal ... whose satisfaction entails possession of the widest range of properties' (Burke I 994, 6Io). The idea here is that sculpture, but not mass of gold, entails possession of aesthetic properties (in addition to chemical properties). ${ }^{5}$

This approach seems mistaken. Suppose a brain (or other physical system) constitutes a mind. Brain entails possession of physical properties but not necessarily mental ones, whereas mind entails possession of mental properties but not necessarily physical ones. Neither sortal dominates the other, on Burke's account, yet it is clear that the brain constitutes the mind and not vice versa. Another sculpture may be constituted by a living branch. Sculpture entails possession of aesthetic but not necessarily biological properties, whereas living branch entails possession of biological but not necessarily aesthetic properties. Again, neither sortal dominates the other, on Burke's account, yet it is clear that the branch constitutes the sculpture and not vice versa.

We will assume, therefore, that a modal analysis is the most promising way to develop an Abelardian account of 'materially constitutes'. In the next section, we'll look at three modal accounts, which are representative of what's available in the literature, and which are prima facie compatible with monism.

4. Some versions of counterpart theory, including Lewis's original account (Lewis I968), work with a single counterpart relation. These versions do not support an Abelardian analysis of modal predicates. Throughout, we will use 'counterpart theory' to mean counterpart theory with multiple counterpart relations (as in Lewis (I986)). This is purely terminological; nothing hangs on this choice.

5. As Burke recognises, mass of gold entails possession of specific properties which sculpture does not (e.g., being composed of gold atoms). But, Burke says, this does not matter: 'What counts, on my criterion, is the entailed range of properties, not the range of specific properties entailed' (Burke I994, 6Iо). 


\section{Modal Analyses of Material Constitution}

In this section, we outline three analyses of material constitution which use modal language. We find all three accounts prima facie plausible as analyses of 'materially constitutes'. Against a background of counterpart theory, these three analyses support the idea that 'materially constitutes' is an Abelardian predicate. As such, all three analyses are prima facie compatible with monism. A monist who takes asymmetrical material constitution claims seriously should accept an account along these lines. Yet, as we will argue in $\$ 4$, the monist can accept none of these accounts.

One way to capture the asymmetry in our material constitution judgements is in terms of persistence conditions or destruction conditions. The mass of gold could have been radically reshaped without destruction in ways the sculpture could not, whereas the sculpture could have lost some of its parts without destruction in ways the mass of gold could not. This approach is captured in the destruction analysis of material constitution (Doepke I982; Simons I987):

DESTRUCTION: $a$ materially constitutes $b$ at time $t$ iff (i) $a$ spatially coincides with $b$ at $t$ and (ii) $a$ could be a substratum of $b$ 's total destruction.

Here, a's being a substratum of $b$ 's destruction means simply that $a$ could survive a change which $b$ could not. But typically, sculptures can survive changes which masses of gold cannot. This is why the notion of a thing's total destruction is required. 'Total destruction' has to be understood in a highly context-sensitive way. To destroy a brick wall totally, for example, it is sufficient to take all of the bricks away; one doesn't need to destroy the bricks themselves. Similarly, one can totally destroy our sculpture by unwinding the gold sheet, thus destroying the form of the sculpture. One doesn't need to destroy the mass of gold which materially constitutes it. We will assume, for argument's sake, that the notion is intelligible. $^{6}$

Given this assumption, we find DESTRUCTION a plausible analysis of materialconstitution statements. The mass of gold materially constitutes the gold sheet, according to DESTRUCTION, because because the mass of gold can survive the kind of radical reshaping - rolling into a solid sphere, for example - which would totally destroy the gold sheet. Similarly, both the mass of gold and the gold sheet materially constitute the sculpture, according to DESTRUCTION. But the converses do not hold. To destroy the mass of gold totally, one must scatter the pieces of gold that make it up. (Removing one small part of the gold will destroy the mass, but will not totally destroy it.) If we scatter the gold in this way, the gold sheet and the sculpture are also destroyed, so neither can survive the total destruction of the mass of gold. But perhaps the sculpture could survive the gradual replacement of small bits of gold with plastic, until little of the original gold is left. If so, we can replace 'total destruction' with 'total, non-gradual destruction' in DESTRUCTION.

6. Perhaps the notion is too imprecise to be used in a genuine analysis. As we will argue that the monist cannot use DESTRUCTION in her analysis of 'materially constitutes', it will not damage our point if it turns out that the notion of total destruction is a defective one. 
Were large parts of the gold to be swapped with bits of plastic relatively quickly, both the gold sheet and the sculpture would be destroyed, leaving a new sheet and a new sculpture in its place. Since clause (ii) is a modal requirement, DESTRUCTION can treat 'materially constitutes' as an Abelardian predicate and so is prima facie compatible with monism.

An alternative approach to capturing the asymmetry is to contrast what is essential to the sculpture with what is essential to the mass of gold (Jarvis Thomson I998):

ESSENTIAL PARTS: $a$ materially constitutes $b$ at $t$ iff

(i) $a$ spatially coincides with $b$ at $t$;

(ii) something is an essential part of $a$ at $t$, no part of which is an essential part of $b$ at $t$; and

(iii) all essential parts of $b$ at $t$ have a part which is essential to $a$ at $t$.

Let us see how this account works in our example. The mass of gold and gold sheet are spatially coincident. There is a fingernail-size piece of gold $g$ in the left-hand side of the gold sheet which is essential to the mass of gold (for, were it to be removed or destroyed, there would remain some other mass of gold). But it is not essential to the gold sheet, for one could remove or destroy $g$ without destroying the gold sheet. One would then have a damaged gold sheet, but nevertheless the same sheet as before. So condition (ii) is met. Now take any essential part of the sheet (say, its left half). This has gold parts, all of which are essential to the mass of gold, and so condition (iii) is met. Hence ESSENTIAL PARTS correctly says that the mass of gold materially constitutes the gold sheet. In the same way, ESSENTIAL PARTS correctly says that the mass of gold materially constitutes the sculpture.

A monist can read 'is an essential part of' as an Abelardian predicate, so that 'bit of gold $g$ is an essential part of the gold sheet' and 'bit of gold $g$ is not an essential part of the sculpture' are jointly consistent with 'the gold sheet is numerically identical to the sculpture'. Hence ESSENTIAL PARTS is prima facie compatible with monism.

The final account of material constitution we consider here, due to Rudder Baker (2000), focuses on the idea that in appropriate circumstances a mass of gold will be spatially coincident with a sculpture, whereas masses of gold in general need not be spatially coincident with sculptures. Circumstances are sculpturefavourable when every property that must be exemplified for something to be a sculpture, other than primary kind properties such as being a mass of gold, being an sculpture etc, is in fact exemplified (Rudder Baker 2000, 42). This includes the mass of gold having an appropriate form for a sculpture (and having that form as the result of a sculptor's actions, rather than a freak natural occurrence). The appropriate community must also recognise a suitably-shaped and suitably-created mass as a sculpture and treat it as such.

The analysis then holds that the mass of gold materially constitutes the sculpture because a mass of gold necessitates the existence of a spatially coincident 
sculpture in sculpture-favourable circumstances, whereas masses of gold in general need not be spatially coincident with sculptures. In general (Rudder Baker 2000, 95),

FAVOURABLE CiRCUMSTANCES: $a$ materially constitutes $b$ at $t$ iff there are distinct kinds $F$ and $G$ and $G$-favourable circumstances $C$ such that:

(i) $a$ spatially coincides with $b$ at $t$;

(ii) $a$ is essentially $F$ at $t$ and $b$ is essentially $G$ at $t$;

(iii) $a$ is in circumstances $C$ at $t$;

(iv) it is necessary that: for any object $x$ and time $t^{\prime}$, if $x$ is essentially $F$ and $x$ is in circumstances $C$ at $t^{\prime}$, then there is some object $y$ which is essentially $G$ and which spatially coincides with $x$ at $t^{\prime}$; and

(v) it is possible that: $a$ exists and there is no time $t^{\prime}$ and object $x$ which is essentially $G$ and which materially coincides with $a$ at $t^{\prime}$.

If clauses (iv) and (v) are treated in the counterpart-theoretic way, then FAVOuRABLE CIRCUMSTANCES will treat 'materially constitutes' as an Abelardian predicate. So FAVOURABLE CIRCUMSTANCES is prima facie compatible with monism.

This concludes our look at modal analyses of material constitution. We find all the accounts prima facie plausible. A monist who takes asymmetric material constitution judgements seriously needs to accept some account along these lines. In the next section, however, we argue that a monist cannot accept any of these accounts and that there is reason for thinking that she cannot accept any other account along similar lines.

\section{The Problem for Monism}

In this section, we will argue that, despite initial appearances, DESTRUCTION, ESSENTIAL PARTS and FAVOURABLE CIRCUMSTANCES are not compatible with the monist metaphysics. Combined with monism, they straightforwardly give the wrong results for a wide variety of cases (for which they do give the right results when combined with pluralism). We take this to show that the modal Abelardian reading of 'materially constitutes' is not available to the monist.

Our argument begins by noting that, according to the monist, the sculpture, the gold sheet and the mass of gold are one entity. So that entity may be referred to as such, using complex descriptive phrases like: ${ }^{7}$

(D) the mass of gold that's also a sculpture;

the sculpture that's also a gold sheet;

the thing that's both a mass of gold and a gold sheet;

the thing that's both a mass of gold and a sculpture.

7. Throughout, we will assume that these definite descriptions are uniquely satisfied by our example sculpture. 
For the monist, these descriptions are all perfectly good ways of picking out our sculpture. ${ }^{8}$ So she must have something to say about judgements such as:

(I) the thing that's both a mass of gold and a gold sheet makes up (materially constitutes) the statue.

(2) the thing that's both a mass of gold and a sculpture makes up (materially constitutes) the gold sheet; and

(3) the gold sheet makes up (materially constitutes) the thing that's both a mass of gold and a sculpture.

These statements concern the one-to-one relation material constitution. ${ }^{9}$ It seems obvious to us that (I) is acceptable, given the monist world-view. The sculpture is made up of a gold sheet and made of a mass of gold, and it is not stretching things too far to assert (I) as a way of summing that up, given willingness to use the compound term. (2) and (3), however, are another matter, for they are bizarre. Being a sculpture can have no material-constituting role in relation to a gold sheet, but (2) implies that it does; being a gold sheet can have no material-constituting role in relation to a mass of gold, but (3) implies that it does. In what follows, therefore, we will assume that (2) and (3) are false.

We now argue that DESTRUCTION gives the monist the wrong results for (2) and (3). Consider the thing that's both a mass of gold and a sculpture. It spatially coincides with the gold sheet. Now suppose we cut the gold sheet and lay it flat, thereby destroying the sculpture. We take this to be the total destruction of the sculpture. (Recall that the total destruction of an artefact doesn't require the annihilation of its constituting matter. Removing all the bricks totally destroys the brick wall. Completely altering a sculpture's form totally destroys the sculpture.) If the sculpture is totally destroyed, then there's no longer a thing that's both a mass of gold and a sculpture: that thing has been totally destroyed too. ${ }^{\text {IO }}$ But the gold sheet survives being flattened out, hence it can survive the total destruction

8. We do not think there can be any good objection to the use of complex referring terms such as these. Clearly, one can talk of the sculpture and great work of art before us. Moreover, our argument could be put in terms of the complex demonstrative 'that sculpture and mass of gold', or we could have used 'DTHAT(the thing that is both a sculpture and a mass of gold)' (Kaplan I978). On most views of complex demonstratives, 'that bald man' will refer only to someone who is both bald and a man, and such terms certainly refer some of the time. So there can be no general problem with complex referring terms such as (D).

9. Since the relation is one-to-one, 'makes up' picks out material constitution, not composition (see fn 3). It is worth testing both 'makes up' and 'materially constitutes' versions against your intuitions: ours agree in each case.

Io. Couldn't it be that the thing that's both a mass of gold and a sculpture survives, but not as a sculpture? A defender of DESTRUCTION cannot agree. She cannot say that the statue survives but as a mass of gold, not as a statue, for this would imply that the mass of gold does not materially constitute the statue. She must say that, in the contexts relevant to applying DESTRUCTION, statues are essentially statues. The simplest explanation is that, in the contexts relevant to applying DESTRUCTION, referring to an entity under a predicate ' $F$ ' invokes $F$-counterpart relations, so that the $F$ is essentially $F$. Substituting the complex predicate ' $F$-and- $G$ ' for ' $F$ ', this gives us: in the contexts relevant to applying DESTRUCTION, the $F$-and- $G$ is essentially both $F$ and $G$, and hence is destroyed if it ceases to be an $F$ (and likewise, is destroyed if it ceases to be a $G$ ). In our case, the mass-of-gold-and-sculpture cannot survive as a non-sculpture, and so the objection does not stand. 
of the thing that's both a mass of gold and a sculpture. So DESTRUCTION, together with monism, says that $(3)$ is true. But (3) is not true, and hence the monist cannot use DESTRUCTION in her analysis of material-constitution statements.

Monism and Destruction also give the wrong results for (2). Suppose the gold sheet is carefully heated and shaped into a long, thin, solid cylinder, whilst preserving the overall form of the sculpture. And suppose the relevant art community judge the sculpture to be a modified version of the original (rather than a new sculpture). There is no gold sheet remaining, although all its material remains, for a solid cylinder cannot also be a sheet. In this case, both the sculpture and the mass of gold survive the total destruction of the gold sheet. (Again, the total destruction of the gold sheet does not require the annihilation of its matter.) So DESTRUCTION, together with monism, says that (2) is true. But (2) is not true, and hence the monist cannot use DESTRUCTION in her analysis of material-constitution statements.

Next, we turn to ESSENTIAL PARTS. It too gives the monist the wrong result for (2). First, we need to say what the essential parts of the thing that is both a mass of gold and a sculpture are. It seems clear that, as every bit of the mass of gold is essential to that mass of gold, it is also essential to the thing that is both a mass of gold and a sculpture. And similarly, every part essential to the sculpture is essential to the thing that's both a mass of gold and a sculpture.

As the mass of gold materially constitutes the gold sheet, it follows from essential parts that:

(i) the mass of gold has an essential part $p$, no part of which is essential to the gold sheet; and

(ii) all essential parts of the gold sheet have a part which is essential to the mass of gold.

So $p$ is essential to the thing that's both a mass of gold and a sculpture, and all essential parts of the gold sheet have a part which is essential to the thing that's both a mass of gold and a sculpture. And the thing that's both a mass of gold and a sculpture clearly spatially coincides with the gold sheet. So, given monism, essential parts entails (2): the thing that's both a mass of gold and a sculpture materially constitutes the gold sheet. But (2) is false; hence the monist cannot accept essential parts.

Finally, we turn to FAVOURABLE CIRCUMSTANCES. It too gives the monist the wrong result for (2). Since the mass of gold materially constitutes the gold sheet, FAVOURABLE CIRCUMSTANCES entails that there are circumstances $C^{*}$ (favourable to gold sheets such as ours) such that:

(4) necessarily, for any $x$ that's essentially a mass of gold and in circumstances $C^{*}$, there is a $y$ that's essentially a gold sheet and spatially coincident with $x$.

On the Abelardian account, anything that's essentially both a mass of gold and a sculpture is thereby essentially a mass of gold. Now suppose a thing $x$ that's both a 
mass of gold and a sculpture is in circumstances $C^{*}$. That thing (picked out in that way) is essentially a mass of gold and hence, from (4), there is a $y$ that's essentially a gold sheet and spatially coincident with $x$. So it is necessary that anything that's essentially both a mass of gold and a sculpture will, in circumstances $C^{*}$, be spatially coincident with something that's essentially a gold sheet. Moreover, the thing that's both a mass of gold and a sculpture could exist without being materially coincident with the gold sheet. Take our example from above, in which the statue is constituted by a long, thin gold cylinder, rather than a gold sheet. Assuming both monism and FAVOURABLE CIRCUMSTANCES, it follows that (2) is true. But (2) is false: hence the monist cannot appeal to FAVOURABLE CIRCUMSTANCES.

In this section, we have argued that DESTRUCTION, ESSENTIAL PARTS and FAVOURABLE CIRCUMSTANCES are incompatible with monism. In the next section, we discuss why this is problematic for the monist.

\section{Discussion of the Argument}

Each of DESTRUCTION, ESSENTIAL PARTS and FAVOURABLE CIRCUMSTANCES, when combined with monism, give the wrong results for (I) $-(3)$. But so what? In this section, we argue that this is a serious worry for the monist.

To preserve the asymmetry in our material constitution judgements, the monist needs to explain how 'materially constitutes' can be an Abelardian predicate. As we argued briefly in $\mathbb{2}$, the best option here is to offer a modal account of material constitution. The three modal accounts we discussed above are the ones that feature predominantly in the literature, and we think it likely that any modal account of material constitution would not be different in spirit from one of these. Importantly, although the three we considered are quite different from one another, they all failed in the same way to the same set of examples. This, in our view, highlights an underlying problem in the combination of modal accounts of material constitution with monism. It is strong evidence that any modal account based on the approaches above will likewise (assuming monism) give the wrong results for (I)-(3). If so, then the monist has no way to justify her claim that 'materially constitutes' is an Abelardian predicate.

It is also worth noting that each of the accounts considered above gives the right results for $(\mathrm{I})-(3)$ when combined with pluralism rather than monism. According to the pluralist, $(\mathrm{I})-(3)$ are all false (or truth-valueless, depending on one's account of empty terms), since there is (for the pluralist) nothing that is both a mass of gold and a sculpture. The analyses offered of $(\mathrm{I})-(3)$ by DESTRUCTION, ESSENTIAL PARTS and FAVOURABLE CIRCUMSTANCES will likewise be false (or truth-valueless), and so (I)-(3) will all come out false (or truth-valueless), given pluralism. So where DESTRUCTION, ESSENTIAL PARTS and FAVOURABLE CIRCUMSTANCES go wrong when combined with monism, they straightforwardly go right when combined with pluralism. To the extent that the modal analyses are plausible in general, we take this as evidence in favour of pluralism over monism.

We should also note that the 'triple-layer' cases of material constitution we have considered here are not devilishly obscure philosophical inventions. We have 
not invoked wizards magically changing properties or preventing events from occurring; we have not invoked far-off worlds with different laws of nature; we have not invoked extended simples, gunk, ectoplasm or non-material beings. The example we have focused on is far more mundane. If the monist wants to take material constitution statements seriously, she needs an account that deals with statements such as (I) $-(3)$. We've argued here that (i) none of the accounts that feature prominently in the literature on material constitution are compatible with monism; and (ii) there is good reason to think that no such account is compatible with monism.

As far as we can see, this leaves the monist with just two options. She can either treat (I)-(3) differently from other material constitution statements, or else give up on the idea that there is a genuine asymmetry to be captured. We consider the former strategy in the next section.

\section{The Reduction Strategy}

Our strategy above was to assume that DESTRUCTION, ESSENTIAL PARTS and FAVOURABLE CIRCUMSTANCES are plausible analyses of material-constitution statements which are prima facie compatible with monism. So we assumed that they provide a good account of statements such as 'the mass of gold materially constitutes the sculpture' for the monist and pluralist alike. We then found that they go wrong (against a background of monism) with statements such as (2) and (3), which involve complex noun-phrases.

This very fact - that the monist's use of DESTRUCTION, ESSENTIAL PARTS and FAVOURABLE CIRCUMSTANCES goes wrong only in the case of complex nounphrases - is suggestive. Perhaps the monist can give an account which reduces those problematic complex cases to the simpler cases, such as 'the mass of gold materially constitutes the sculpture', which we assumed to be unproblematic for the monist. This is the idea we discuss in this section. It goes as follows.

Reduction: The thing that's both $F$ and $G$ materially constitutes $x$ at $t$ iff

(i) the $F$ materially constitutes $x$ at $t$; and

(ii) the $G$ materially constitutes $x$ at $t$.

This gives the monist the right results: (I) comes out true, whereas (2) and (3) come out false. Indeed, it seems to explain why we have the intuitions we have about (I)-(3). We take (I) to be true because both the mass of gold and the gold sheet materially constitute the sculpture. But we take (2) to be false because the sculpture plays no role in materially constituting the gold sheet. This is precisely what REDUCTION predicts.

We find two problems with REDUCTION. First, the 'if' direction of REDUCTION does not hold when the $F$ and the $G$ are distinct (which the monist takes to be the case when they are merely temporarily coincident). Then, (i) and (ii) may both be true even though nothing is both $F$ and $G$. If so, the left-hand-side of 
REDUCTION is false (or truth-valueless, depending on one's theory of empty terms), and hence REDUCTION is false. So REDUCTION can hold only in cases of permanent coincidence (i.e. in cases which, according to the monist, are cases of identity). But this is bizarre: we should not have one analysis of ' $x$ materially constitutes $y$ ' for the case when $x=y$ and another for when $x \neq y$.

The second problem with REDUCTION is as follows. REDUCTION is not, strictly speaking, a thesis about how 'materially constitutes' works, but rather a thesis about how complex noun-phrases work in Abelardian contexts. It says that predicate conjunction is to be analysed as wide-scope sentential conjunction: in the Abelardian context ' $\phi(-)$ ', ' $\phi$ (the $F$-and- $G$ )' is analysed as ' $\phi$ (the $F) \wedge \phi($ the $G)$ '. This is specifically not a claim about how the Abelardian context ' $\phi(-)$ ' interacts with the linguistic context. Linguistic context determines which counterpart relation is in play; it is not a mechanism which can transform a predicate conjunction into a wide-scope sentential connective in the way REDUCTION prescribes. Rather, the claim must be one about how predicate conjunction behaves within Abelardian contexts.

If the claim is right, then predicate conjunction should behave this way within comparable Abelardian contexts. But this is clearly not the case. Consider, for example:

(5) the thing that's both $F$ and $G$ is essentially both $F$ and $G$

which is clearly not equivalent to

(6) (the thing that's $F$ is essentially both $F$ and $G$ ) $\wedge$ (the thing that's $G$ is essentially both $F$ and $G) .{ }^{\text {II }}$

Similarly,

(7) the thing that's both a mass of gold and a sculpture could exist in circumstances in which either the mass of gold does not exist or the sculpture does not exist.

is not equivalent to the conjunction of

(8) the mass of gold could exist in circumstances in which either the mass of gold does not exist or the sculpture does not exist; and

(9) the sculpture could exist in circumstances in which either the mass of gold does not exist or the sculpture does not exist.

Both (8) and (9) are true. The mass of gold could exist in sculpture-less circumstances, and the sculpture could exist even if the mass of gold has been destroyed (e.g., if that particular mass of gold has been destroyed through losing one small part). Yet (7) is not true, for if either the sculpture or the mass of gold

II. As we noted above, the sculpture doesn't contain little bit of gold $g$ essentially, whereas the thing that's both a sculpture and a mass of gold does. 
fail to exist, then nothing is both the mass of gold and the sculpture. In both cases, treating the predicate conjunction as a wide-scope sentential conjunction clearly gives the wrong results. We see no reason to think that predicate conjunctions work in the way required by REDUCTION in the case of material constitution statements, when they clearly do not work that way in other Abelardian contexts.

In this section, we've argued that REDUCTION is viable only against a background theory of how complex noun-phrases behave in Abelardian contexts. As the required background theory gives the wrong results for other Abelardian contexts, we do not find REDUCTION to be viable.

\section{Conclusion}

We argued at the beginning of this paper that material constitution is an asymmetric relation $(\mathbb{I})$. We then argued that the monist has serious trouble in dealing with asymmetric material constitution statements. The only plausible monist strategy for explaining 'materially constitutes' is as an Abelardian predicate and hence as a modal predicate $(\mathbb{2})$. But the representative modal analyses of material constitution we considered $\left(\mathbb{S}_{3}\right)$ are incompatible with monism $\left(\mathbb{S}_{4}\right)$, for they give incorrect results for statements (I) $-(3)$. This gives us good reason to think that, given monism, no modal account of material constitution will give the right results for $(\mathrm{I})-(3)\left(\$_{5}\right)$. If so, the monist has no justification for taking 'materially constitutes' to be Abelardian. Without Abelardian resources, the monist cannot save any appearance of asymmetry in material constitution statements. Pluralists face none of these worries (although they do face others). The pluralist can accept that there is a genuine asymmetric relation of material constitution that holds between distinct entities.

Must one take 'materially constitutes' to be asymmetric? We think there is considerable virtue in the reasons highlighted in $\mathbb{S}$. The idea of material constitution is not a mere conceit of metaphysicians. It's a working concept used in expressing our interest in what makes up the things that interest us. Material constitution claims can express constructive recipes for making things. That's why we have the concept: it wouldn't be around otherwise. Recipes for making up things are in the same set of procedures for manipulating the world as causal recipes. Material constitution claims track recipes for making. The latter are asymmetric and so, consequently, is material constitution.

\section{References}

Burke, M. (I994). 'Preserving the Principle of one Object to a Place: a Novel Account of the Relations Among Objects, Sorts, Sortals, and Persistence Conditions,' Philosophy and Phenomenological Research, 54, pp. 591-624.

Burke, M. (I997). 'Persons and Bodies: How to Avoid the New Dualism,' American Philosophical Quarterly, 34, pp. 457-467.

Doepke, F. (I982). 'Spatially Coinciding Objects,' Ratio 24, pp. 45-6o. 
Fine, K. (2003). 'The Non-Identity of a Material Thing and Its Matter', Mind I I 2, pp. I95-234.

Gasking, D. (I95 5). 'Causation and Recipes,' Mind 64, pp. 479-487.

Gibbard, A. (1975). 'Contingent Identity', Journal of Philosophical Logic 4, pp. I87-22 I.

Kaplan, D. (1978). 'Dthat.' in Syntax and Semantics, ed. P. Cole, New York: Academic press, pp. 22I-253.

Lewis, D. (I968). 'Counterpart Theory and Quantified Modal Logic,' The Journal of Philosophy 65, pp. II3-I 26.

Lewis, D. (I97I). 'Counterparts of Persons and Their Bodies,' The Journal of Philosophy 68 , pp. 203-2II.

Lewis, D. (I986). On the Plurality of Worlds, Blackwell: Oxford.

Lowe, E. (1983). 'Instantiation, Identity and Constitution,' Philosophical Studies 44, pp. $45-59$.

Noonan, H. (I99I). 'Indeterminate Identity, Contingent Identity and Abelardian Predicates,' The Philosophical Quarterly 4I, pp.I83-I93.

Rudder Baker, L. (2000). Persons and Bodies: A Constitution View, New York: Cambridge University Press.

Simons, P. (1987). Parts: A Study in Ontology, Oxford: Clarendon Press.

Jarvis Thomson, J. (I997). 'Parthood and Identity Across Time,' in Material Constitution, ed. M. Rea, Lanham: Rowman \& Littlefield, pp. 25-43.

Jarvis Thomson, J. (I998). 'The Statue and the Clay' Nô̂s 32, pp. I49-I73.

Wasserman, R. (2004). 'The Constitution Question,' Nô̂s 38, pp. 693-7Io.

Wiggins, D. (1980). Sameness and Substance, Oxford: Blackwell.

Yablo, S. (I987). 'Identity, Essence, and Indiscernibility' The Journal of Philosophy 84, pp. 293-3I4. 